Civil Engineering

Volume 170 Issue CE6

Crossrail project: procuring infrastructure for London's Elizabeth line

Lloyd-Davies and Rowark
Proceedings of the Institution of Civil Engineers Civil Engineering 170 November 2017 Issue CE6 Pages 35-41 http://dx.doi.org/10.1680/jcien.17.00002 Paper 1700002

Received 27/01/2017 Accepted 07/06/2017

Keywords: contracts \& law/procurement/project

management i

\title{
Crossrail project: procuring infrastructure for London"s Elizabeth line
}

1 Kevin Lloyd-Davies BA, Dip FM (CEM), FRICS, MBIFM Head of Procurement, Crossrail Limited (2014-2017), London, UK
2 Martin Rowark FRICS

Procurement Director, Crossrail Limited (2009-2014), London, UK

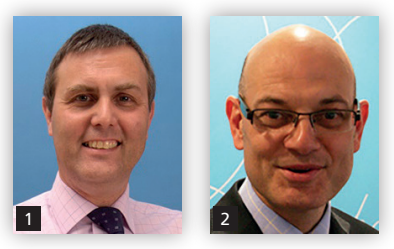

This paper sets out the origins and approach to procurement on Crossrail, the development of the 'six pillars' of procurement and how these were deployed to deliver over $\mathbf{f 1 1}$ billion of capital spend over a 5 year period. Initial reservations about retrofitting the approach into the existing governance processes were overcome by demonstrating clear gains through forward planning, managing risk early in the process and promoting efficiencies in production. The approach allowed a $30 \%$ reduction in the procurement team size while delivering the same outputs. In addition, all critical key dates were met, there were no successful challenges and the scope was procured within budget estimates.

\section{Introduction}

The $£ 14.8$ billion Crossrail project to deliver the new Elizabeth line east-west railway across London has been one of the largest regulated procurements undertaken in the UK in recent times. This paper provides a summary of the origins and approach to procurement at the publicly owned delivery organisation Crossrail Limited, the development of the 'six pillars' of procurement and how these were deployed to successfully deliver over $£ 11$ billion of capital spend over a 5 year period.

The procurement approach on Crossrail was subsequently adopted by Infrastructure UK (now the Infrastructure and Projects Authority (IPA)), forming the basis of its procurement module in the project initiation routemap (IPA, 2016). Much of Crossrail's procurement learning legacy is now incorporated in this module and provides helpful guidance when initiating procurement on major programmes in the UK.

The six-pillar approach was developed from procurement best practice employed by the UK Olympic Delivery Authority for delivering venues and infrastructure for the London 2012 Olympic and Paralympic Games.

As well as delivering scope and programme requirements, other policy aims were set for Crossrail by its stakeholders. It was tasked with ensuring that procurement encompassed these aims in its approach to delivery. These are also briefly discussed in this paper.

\section{Procurement approach and governance}

In its transition from before to after royal assent of the Crossrail Act 2008, Crossrail Limited considered how the complex scope and the policy aims were to be procured and the best model to be deployed. At the time, the team wanted to secure similar best practice results to London 2012. Additionally, Crossrail Limited was obligated under the project development agreement to deliver the requirements set out under the 2008 Act and by its stakeholders.

The key procurement policy aims included

- providing best affordable value in delivering Crossrail project objectives

- conducting activities in a fair, objective and transparent manner

- complying with the regulatory framework of all relevant legislation, governance and audit frameworks and delegated levels of authority

- using best practice in applying ethical standards

- aligning with Crossrail Limited vision and values

- adhering wherever appropriate to government procurement policies and Transport for London and Greater London Authority responsible procurement policy.

During transformation into a delivery organisation and at the start of the procurement phase, Crossrail Limited recognised that there needed to be a greater emphasis on the procurement structure. The highly successful 'purchase and supplier engineering' procurement approach used at London 2012 Olympics was developed and employed on Crossrail (Figure 1). It was not fully adopted until April 2011, following a 6 month development phase from October 2010.

The concepts developed in the purchase and supplier engineering model were redefined by the procurement team into a series of procurement steps. These steps were encapsulated in a document called the 'procurement code', which governed the deliverables required of the procurement function. A governance model was also developed to support this and incorporated into the code. It was based on 12 procurement deliverables and linked the points at which programme and procurement governance was required (Figure 2).

The programme complexity and schedule deadlines ultimately drove a need for 'industrialised' processes in procurement. A major change from its pre-assent condition was therefore required and 
Civil Engineering

Volume 170 Issue CE6
Crossrail project: procuring infrastructure

for London's Elizabeth line

Lloyd-Davies and Rowark

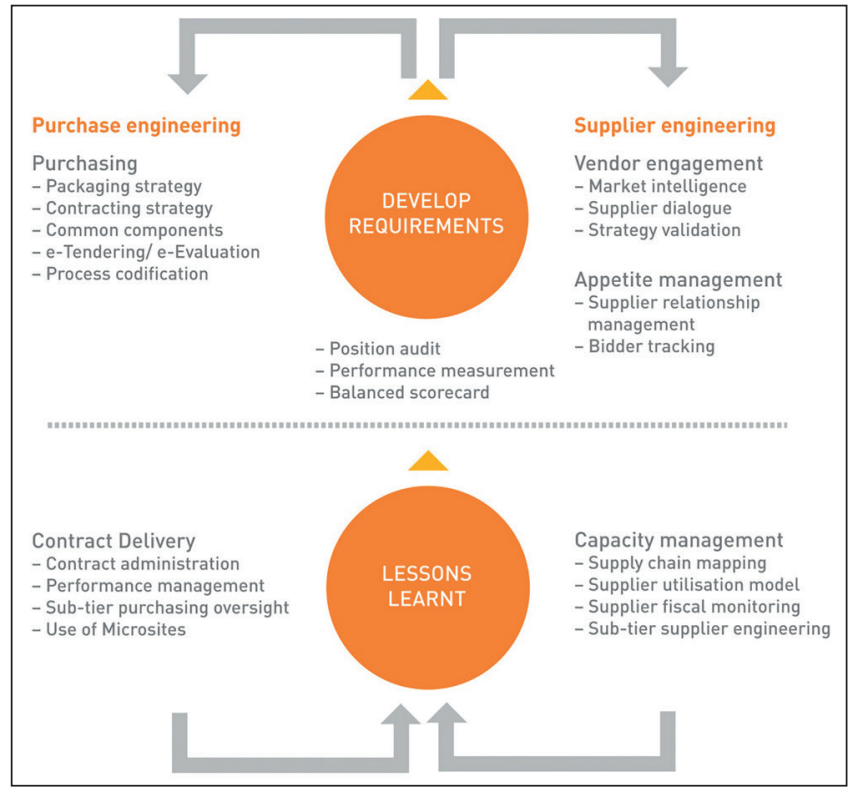

Figure 1. Procurement and supplier engineering model (Mead and Gruneberg, 2012) implemented. Crossrail needed good project and production management using modern procurement practices. The procurement policy went through extensive consultation and was aligned with the delivery policy prior to publication. Key elements were then combined with procurement guidance to create the procurement code, which became the governance tool for procurement.

Early determination of policy objectives was fundamental to Crossrail procurement in two aspects

- to crystallise policy aims into firm policy objectives, supported by the board, with functional consensus at the outset - this minimised the opportunity to change objectives during the course of the procurement process or subsequent contract delivery

- to establish policy objectives that were flowed into the tender documents for evaluation and then included into subsequent contracts for compliance.

The result was that procurement became the principal instrument to drive forward and include more progressive criteria driven by policy objectives. This was in addition to the traditional evaluation criteria of cost, time and quality. These policies were developed into the Crossrail programme functional requirements, which detailed the outcomes for delivery together with performance metrics.

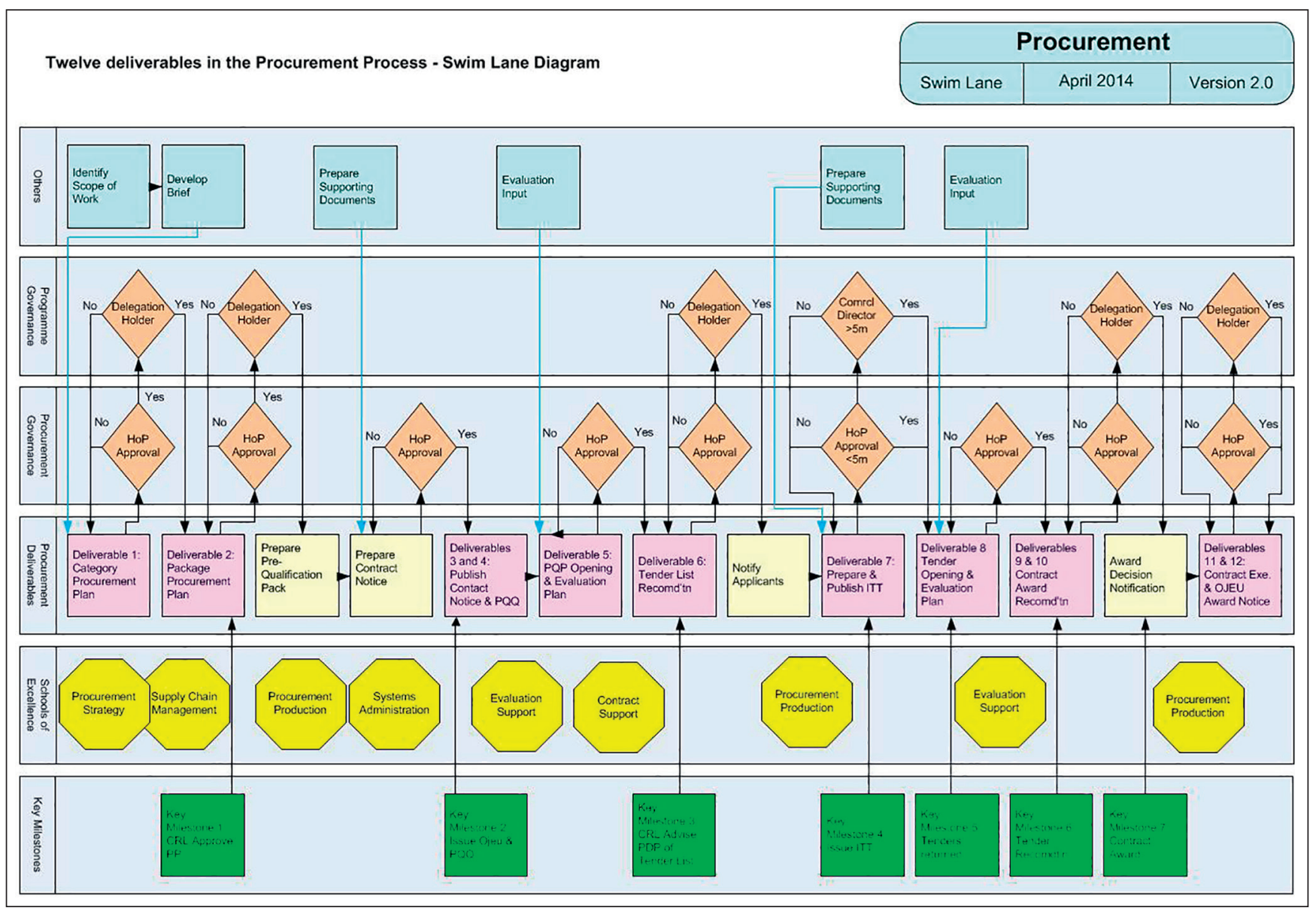

Figure 2. Procurement governance - swim-lane diagram. CRL, Crossrail Limited, HOP, Head of Procurement; ITT, invitation to tender; OJEU, Official Journal of the European Union; PDP, projects delivery partner; PP, programme partner; PQQ, pre-qualification questionnaire 
Civil Engineering

Volume 170 Issue CE6
Crossrail project: procuring infrastructure

for London's Elizabeth line

Lloyd-Davies and Rowark

\section{Key steps to success - the six-pillar approach}

Purchase and supplier engineering was used as the basis for procurement at Crossrail and was further developed into a six-pillar model (Figure 3). A major structural change to the procurement function was implemented in late 2010 to deliver against this sixpillar model. The elements were

1. understanding and communicating the 'requirements'

2. understanding and engaging the 'markets'

3. developing a 'packaging' strategy (managing and optimising the interfaces)

4. developing a 'contracting' strategy (risk allocation and transaction)

5. defining a 'route' to market

6. communicating the 'benefits'.

Initially, there were some reservations as to whether the model could be implemented as it would require retrofitting into the existing governance processes. However, these were overcome by demonstrating clear gains through forward planning (category and procurement plans), managing risk early in the process and promoting efficiencies in the production processes.

The approach allowed a reduction in the procurement team size from 63 to $40(30 \%)$ while delivering the same outputs. Further evidence of this success was meeting all critical key dates, having no successful challenges and scope procured within budget estimates.

\subsection{Requirements - pillar 1}

The Crossrail programme functional requirements set out a series of detailed outcomes to measure Crossrail's success. These outcomes were broken down into the output requirements for each project. Priority themes were developed by the senior management team to underpin delivery in the form of a statement of the company vision and a set of values: safety, inspiration, respect, collaboration and integrity.

Work to align suppliers with Crossrail's vision has proven effective. There has been success around skills and employment as well as engagement with small- and medium-sized enterprises through the supply chain. In general, the absence of a balanced scorecard at the start of procurement was a lost opportunity to fully align the requirements.

However, each functional Crossrail team was engaged to ensure that the programme functional requirement outcomes for delivery, together with the performance metrics, were embedded within the tender and contract documentation. Flow-down of the requirements was core to the delivery of the procurement strategy and in the development of tendering criteria.

The formulation and compilation of requirements, suitable for inclusion into contracts, was a significant task. The precision of language required for the NEC3 contract works and service information presented a significant challenge to the specifiers.

A key lesson learned from the requirements pillar was for the functions to draft their documents based on a developed balanced scorecard linked to the programme objectives, selection criteria and key performance indicators. This should be done in a way that clearly and robustly articulates them to the project team, supply chain and suppliers.

Guidance feedback for pillar 1 included

- review all aspects of the approved business case and clearly establish the requirements

- engage and consider the aims and objectives of all stakeholders

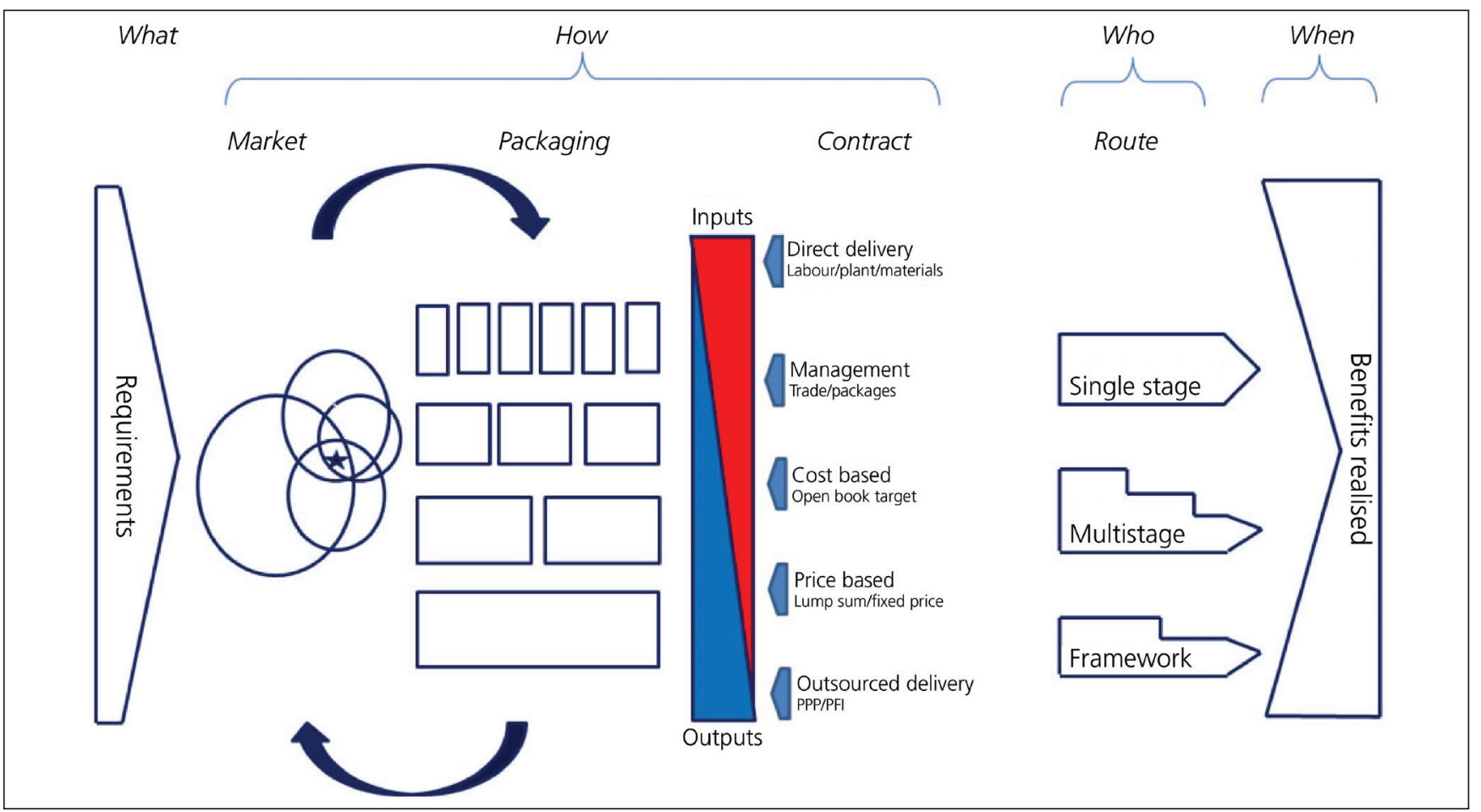

Figure 3. Six-pillar approach; PPP, public-private partnership; PFI, private finance initiative 
Crossrail project: procuring infrastructure

for London's Elizabeth line

Lloyd-Davies and Rowark
- establish a timetable for actions going forward

- look to develop a policy document

- consider developing a balanced scorecard to enable procurement in a manner that delivers on all priorities and objectives.

\subsection{Markets - pillar 2}

Crossrail Limited identified the market environment in which the project operated and then engaged with it at the earliest opportunity. This allowed the market to be tested on various options or, more specifically, gauge its reaction to risk transference, technical solutions, funding, interfaces, methodology and programme. Market appetite was then assessed and incorporated into the packaging strategy. Good responses indicated a healthy appetite and higher competition. This engagement was an iterative process so that intelligence was fed into procurement at various stages.

The engagement process was managed by the supply chain management team embedded within procurement and included market engagement, market and supply chain analytics, and promoting economic sustainability. This enabled the programme to be informed about the market position in three key risk areas market appetite, capacity and capability. This intelligence was used for the development of procurement strategies, tender analysis and risk management during delivery.

A key engagement strategy was to make Crossrail Limited an entity easy to do business with by encouraging behaviours that were fair and equitable to both parties. The delivery team was also mindful that it did not present unreasonable expectations of risk transfer to the supply chain. The cost of bidding was also uppermost in the minds of both the delivery team and the market, so solutions that could minimise this would be attractive to the parties. This strategy, in conjunction with the economic cycle, elicited a positive response from the market and therefore no failures in competition or lack of response.

Market behaviour was influenced by Crossrail Limited's preparedness to engage. Part of this included selling the project to the market. This was done by engaging early with clear messaging and adopting a consistent approach. This in turn strengthened the delivery team's understanding of the supply chain's appetite, capacity and capability.

Market intelligence gave an indication of how the market would respond to the opportunity; for example, joint-venture solutions

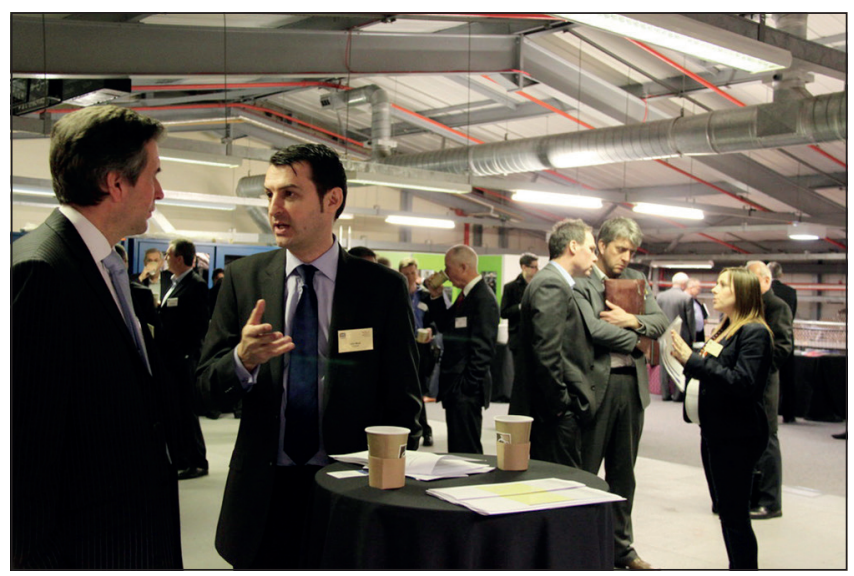

Figure 4. Supply chain engagement event were proposed where there were shortfalls in capacity or capability within individual companies. This in turn influenced the way the packaging strategy was constructed, for example by considering smaller scope boundaries or acceptance that joint ventures were the right solution to the proposed scope.

The supply chain management function monitored the financial performance of critical suppliers in the chain. Approximately 7000 suppliers were assessed and this assessment was based on a range of data sources (around 100 in number) that allowed, by exception, reporting of the supplier performance to be undertaken on a daily basis. The performance measures included speed of payment, solvency and percentage of turnover being secured.

The socio-economic and environmental requirements formed the foundation of the programme's sustainability strategy and served it well in guiding and directing a range of other policies, strategies and local initiatives.

A number of regional events were organised to engage with companies across the whole of the UK (Figure 4). Some of these were more successful than others. There was a perception in the market that Crossrail was a London-centric project and that firms outside south-east England could not be competitive. These events and roadshows were the delivery team's response to counter this perception by positively encouraging more engagement across the UK.

The data collected by the supply chain management team provided evidence that the project was having an impact across the whole of the UK, not just the in the south-east. The delivery team was able to provide data in a number of formats, including supplier heat maps, tracing the Crossrail pound and opportunity tracking (Figure 5).

The supply chain management team led economic sustainability initiatives, particularly the maximisation of opportunities for small to medium enterprises and other suppliers in developing economic areas of the UK. During the procurement phase, the supply chain management and wider client team engaged with over 8000 business representatives to advance these initiatives.

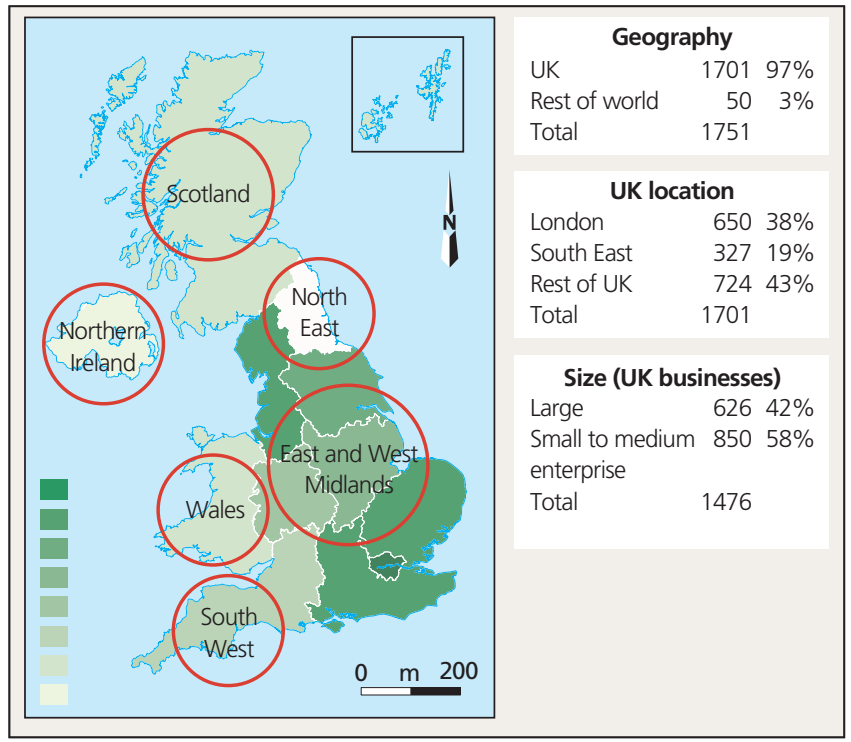

Figure 5. Typical UK heat map and data on numbers of suppliers collected by the Crossrail supply chain management team (Gardiner \& Theobald) 
Guidance feedback for pillar 2 included

- establish a clear engagement strategy, including the timeline and the format for supplier input

- be aware that early planning and communications are essential elements to deliver a successful engagement strategy

- clearly define the requirements before engagement to avoid confusion and loss of confidence

- be aware that loss of appetite or unexpected market behaviours may result if the engagement is not considered carefully, leading to poor feedback, lack of competition, failure in market intelligence and a poor packaging strategy

- know your market: have a good understanding of the market environment in which you are operating

- understand the need to communicate fully the essential details to the market so that suppliers can match capability, capacity and appetite to the opportunity being presented

- use existing networks, trade associations, industry bodies, umbrella bodies and so on

- have a feedback process to ensure that any market intelligence is fed back to the relevant team

- feed intelligence back into the procurement approach.

\subsection{Packaging - pillar 3}

Packaging was at the heart of this procurement model and was fundamental to success in delivery. The purpose of having a packaging strategy was to plan and coordinate the scope to be delivered by different markets. This packaging process was to bring detail to the procurement and delivery strategies through a works package procurement plan that would be used in the procurement process (Figure 6).

Some of the key drivers considered when packaging the scope were the creation of potential physical and contractual interfaces, the market in which the project operated, value for money, technical characteristics of the scope (including methodology and time constraints), commonality, and the structure and availability of funding (internal or private finance options).

Many options were considered and analysed, ranging from multiple packages to single large packages. It was therefore imperative to engage fully with the market to test the strategy. Ongoing feedback and engagement enabled the packaging

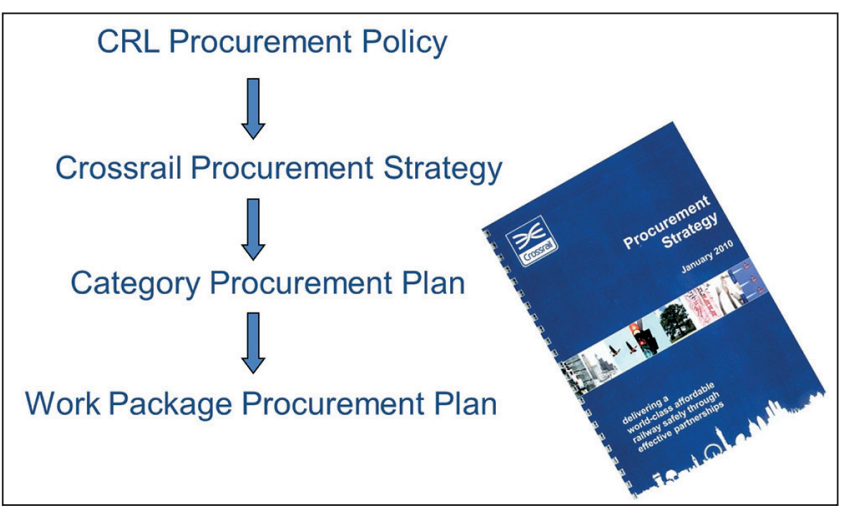

Figure 6. Flow-down of procurement policy into a detailed works procurement package plan. CRL, Crossrail Limited strategy to be continually refined, providing confidence that its approach was robust and that the market was able to deliver the scope.

The main functions of the packaging strategy were to ensure that the scope was fully deliverable by the most appropriate market, to optimise the number of interfaces to meet the requirements and minimise risk at the best value, and to generate appetite for the maximum level of competition from the market.

The categories comprised aligned works, services or products, and were flexible enough to accommodate additional scope, allow the facility for collaboration and provide access to commonality. Categorisation also provided consistency in the tendering process, allowing bidders to become familiar with documents, risk allocation, pricing requirements and the criteria used in assessing capacity and capability. Standard sets of contract solutions (see Section 3.4) allowed control of the contracting process to remain at a programme level to manage consistency and, therefore, risk.

It was important to categorise similar elements of work, design or services at a high enough level to allow effective communication with the target market. The key themes considered in categorisation were

- the technical aspects of delivery, including methodology and technologies

a the timing of the delivery

- the physical location of the work or service in relation to others (e.g. interfaces)

- the economic benefits

- that the market exists, is recognisable and able to provide healthy competition

- capacity and resource available in the supply chain to deliver the required quantity and quality.

The process resulted in the category structure illustrated in Figure 7. The categorisation of scope enabled the development of detailed works package procurement plans for delivery, with buy-in from the project teams. The packaging strategy influenced the programme in a number of areas - the creation of interfaces between packages and within packages; the value of the works (potential interested contractors or joint ventures); the scope of the works (type of contractors required); the type, extent and cost of the client's project management organisation; the level of design to be undertaken by the contractor and the corresponding approval process required of the client; and health and safety responsibilities including principal contractor roles under the CDM regulations.

Guidance feedback for pillar 3 included

- obtain the total scope and requirements to facilitate a good packaging strategy

- properly assess the package boundaries to ensure that the correct delivery solution is procured

- account for key deliverables, such as the date for operational commencement

- determine the packaging strategy in advance of the contract

- be aware that the strategy needs to consider the drivers that affect the organisation's appetite for risk

- structure the organisation to manage the proposed packaging strategy and risk profile 


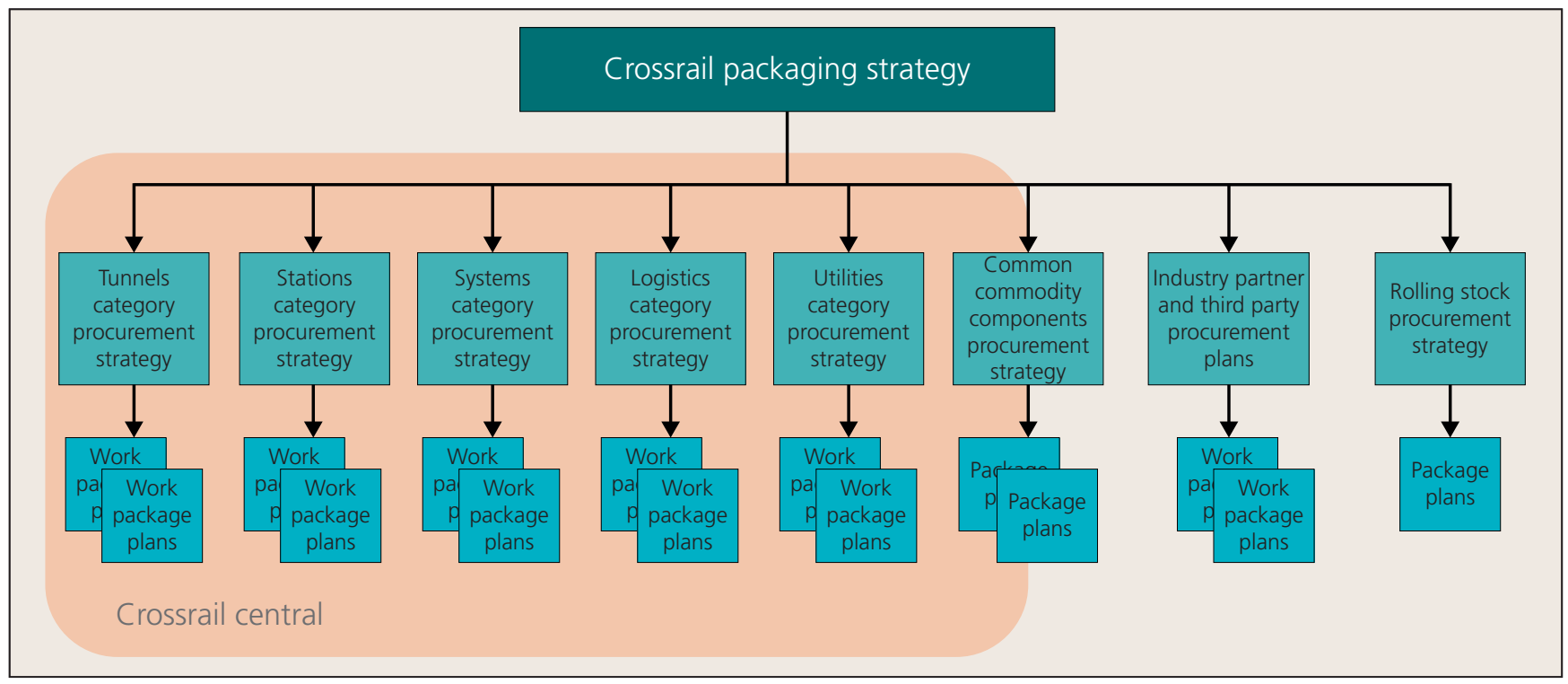

Figure 7. Category structure

- having considered the appetite for risk, determine a suitable allocation of scope; market engagement should be designed to assist with this

- pay particular attention to interface management and the risks associated with it

- manage soft interfaces through collaborative behaviours

- make the packages attractive to the market.

\subsection{Contracting - pillar 4}

The principles underlining the project's approach to contracting were to balance and facilitate a sustainable transfer of risk to the party best placed to manage that risk. Being considered best practice, Crossrail Limited elected to use the government's preferred NEC3 suite of contracts. This was set out as a policy requirement in the procurement policy document. There are a number of reasons for this, among which are the principles of mutual trust and cooperation and robust auditable contract management processes.

The main NEC3: Engineering and Construction Contract enabled the delivery team to use a suite of options appropriate to the risk profile it wished to transact. These were essentially based on the level of design and specification maturity and/or schedule necessity. The contracting strategy is the process of allocating the risk to the party best placed to manage that risk, having determined the client organisation's appetite and how much the market is willing to bear, as established during the packaging phase.

The main functions of the contracting strategy were thus to take account of scope and design maturity risk in an appropriate way, to ensure that the risk was allocated to the party best placed to manage it, to determine that the market was able to bear the proposed level of risk and to select the most appropriate form of contract to manage that risk.

When considering risk allocation, the delivery team undertook an assessment using the basic principles of whether to ignore, accept, avoid, reduce, transfer or exploit. These were the determinants in the underlying approach. They generally fell into three categories or classes of ownership - client risk, shared risk and contractor risk. The outcomes were then assessed against the most appropriate risk profile and the option selected.

Crossrail Limited recognised that there are only a limited number of generic options to contracting. The spectrum moves from outcome/output-based service models, such as publicprivate partnerships and private finance initiatives, to input-based models with the direct purchasing of labour, plant and materials. Other approaches pivoted around price- or cost-based contracts, such as lump sum fixed price or cost reimbursable (often with incentivisation). It was with this contracting palette in mind that Crossrail Limited considered its options for optimising risk transfer. Figure 8 illustrates these points.

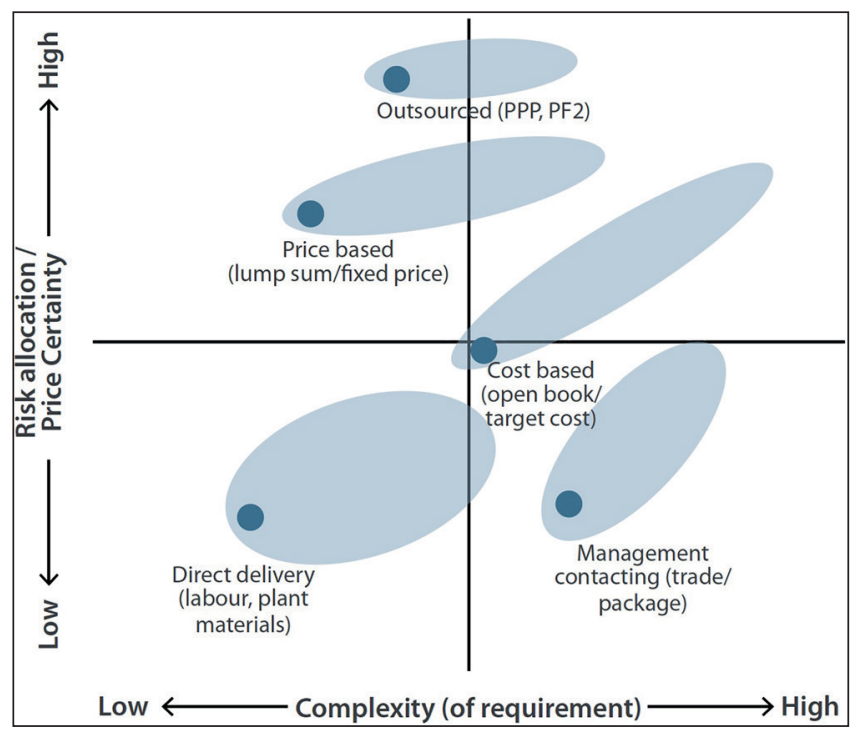

Figure 8. Optimising risk transfer (IPA, 2016). PF2. Private Finance 2 (government contract) 
Guidance feedback for pillar 4 included

- reflect the packaging strategy's intent

- establish the client organisation's and the market's appetite for risk before a contracting strategy is finalised

- allocate risk to the party best placed to manage that risk

- consider a classification structure to simplify the risk selection profile

- select the most appropriate contract form and, if possible, have a flexible and consistent approach; consider a suite of contracts

- establish the level of control required in the contract; determine if the client organisation is able to administer the contracts and whether the senior management team is supportive of the approach

- consider incentivisation, collaboration and associated behaviours

- take account of softer requirements such as skills and employment.

\subsection{Routes - pillar 5}

The route to market is the last stage of the procurement process before contract award. It is characterised by the method of down-selection and the trade-off between competitive leverage, competitive advantage, the degree to which the requirements are developed and the processes used in procurement.

There are various routes to market but they are not discussed here. Further information is available in the IPA routemap procurement module (IPA, 2016), which was developed from the Crossrail and London 2012 experiences.

Crossrail Limited recognised that a trade-off existed between the development of bids before contract award and the amount of competitive leverage that could be obtained for delivery. The cost of design and production planning during the bid process could have been prohibitive and reduced appetite. This in turn could have added unnecessary risk allowances into the bids. In an effort to achieve a balance, the delivery team introduced a process, postaward, called 'optimised contractor involvement'.

The methodology offered the opportunity to review and optimise the design, work production, methodology and innovation in the supply chain. This was a joint exercise carried out within the first 90 days of commencement. It also provided an opportunity for collaboration and early team building. It helped to execute contracts promptly and efficiently - a major benefit considering the scale of the contracting effort and the number of interdependent contracts being let.

Guidance feedback for pillar 5 included

- consider the appropriateness of the route to market to support delivery of the requirements

- develop and understand the level of leverage that needs to be maintained to achieve the desired placement of risk

- determine the balance that must be struck between the level of risk transfer and the time needed to conclude the process

- put in place contingency arrangements should the required risk transfer not be achieved

- consider the cost of bidding to both you and, most critically, your suppliers in advance of selecting the route to market

- establish the impact on the market of a down-selection process; for example, awarding a framework will mean that there is a closed market for the tenure of the agreement

- be aware of the limitations and constraints imposed by EU regulations or other procurement governance requirements.

\subsection{Benefits - pillar 6}

Key obligations for Crossrail Limited when investing public money are that the outcomes of its endeavours have met the requirements and that the lessons learnt are communicated widely for others to benefit.

Like the London 2012 Olympics before it, the Crossrail project leaves a true legacy, not just as tangible infrastructure but also in intellectual property. Programmes can suffer from the natural and sometimes commercial instinct to create something new - a platform upon which to receive recognition. This need to 'reinvent the wheel' stifles progress in many ways rather than evolving and innovating through best practice and, importantly, lessons learned. Programme teams - particularly pop-up programmes - go through the equivalent of a business start-up in almost every case.

This paper is a clear example of the benefits of communication in that it shares the lessons learnt to inform others so that they may take the most effective actions in their own projects or programmes. The procurement benefits evolved at Crossrail have been articulated by the procurement team in collaboration with the IPA. This resulted in the publication of the procurement module of the project initiation routemap (IPA, 2016), which sets out many of the points made in this paper and is the catalyst for learning from the Crossrail procurement team.

The full realisation of benefits will not truly be known until Crossrail is fully operational. However, significant soft benefits have already been delivered, such as skills and employment (the Tunnelling and Underground Construction Academy), environmentally sustainable solutions (Wallasea Island RSPB wetland site, recycling key performance indicators and so on), urban realm improvements and a 'zero harm' approach to safety. Many of these benefits have been derived from the supply chain through the procurement process as priority themes.

Guidance feedback for pillar 6 - at its simplest level - is to assess whether the asset or service has delivered the required outcomes and the lessons learnt have been communicated.

\section{Acknowledgements}

The authors would like to acknowledge the assistance of John Mead and Peter Sell of Gardiner \& Theobald, who were key members of the procurement team in both the Crossrail and London 2012 projects. An expanded version of this paper is available on the Crossrail Learning Legacy website (http://learninglegacy.crossrail.co.uk/).

\section{References}

Crossrail Act 2008. Chapter 18. Her Majesty's Stationery Office, London, UK. IPA (Infrastructure and Projects Authority) (2016) Improving Infrastructure Delivery: Project Initiation Routemap. Procurement Module. IPA, London, UK. See https://www.gov.uk/government/uploads/system/uploads/attachment data/file/529340/Prourement_Module.pdf (accessed 27/01/2017)

Mead J and Gruneberg S (2012) Programme Procurement in Construction: Learning from London 2012. Wiley-Blackwell, London, UK.

\section{How can you contribute?}

If you would like to comment on this paper, please email up to 200 words to the editor at journals@ice.org.uk.

If you would like to write a paper of 2000 to 3500 words about your own experience in this or any related area of civil engineering, the editor will be happy to provide any help or advice you need. 